Industry funding

\section{Chasing the dollar: why scientists should decline tobacco industry funding}

\section{R E Malone, L A Bero}

\section{Tobacco dollars are a bad bargain}

M

ost tobacco researchers now know how the tobacco industry for decades operated clandestinely to obstruct and obfuscate the scientific evidence that smoking causes cancer and, later, that secondhand smoke causes disease in non-smokers. The tobacco industry's internal documents, released as a result of the US states Attorneys General lawsuits and other legal cases, provide ample evidence that is analysed in an expanding body of work. $^{12}$ What may not be as widely known is that these documents also highlight how the industry used respected scientists to advance its goals. Fields and Chapman's important and well documented case study in this issue of the journal shows that even internationally renowned scientists are not immune to the seductions of industry funding. ${ }^{3}$

What is important for today's scientists to understand is that credibility is perhaps the most desired scientific product for tobacco industry funded research. To illustrate, you need look no further than the internal form used by Philip Morris' Worldwide Scientific Affairs to evaluate the need for scientific research, which explicitly includes "Credibility" as a primary criterion for judging proposed studies (along with Health/Safety, Regulatory, and Product Change). (see fig 1; also available at http://legacy. library.ucsf.edu/tid/bwil7d00). Credibility is essential to the positive public image the tobacco industry cultivates for the purposes of increasing product consumption, influencing public opinion, and soliciting opposition to effective public health policies. ${ }^{4}$

This is only one of the reasons that reputable scientists should view industry funding with scepticism, however. Among the other reasons, as Fields and Chapman show, is that almost no one, regardless of one's pure motivations in conducting scientific research, is unaffected by the need to obtain dollars to do the work. Why was Wynder so anxious to be seen as "not anti-tobacco"? As this case study shows, it was because he wanted to ensure that he could get (and continue to get) money from the tobacco industry. Yes, the industry courted Wynder, but he was also active in chasing dollars, and the documents suggest that he may have thought he could steer a course of self management that would preclude conflicts of interest. Unfortunately, it appears he was unsuccessful.

Why didn't Wynder openly acknowledge tobacco industry sponsorship? Was he discomfited by the tobacco industry's pressure (for example, to delete any mention of smoking and health from the press materials for his American Health Foundation opening)? Was he aware that the industry was manipulating presentation of his findings, and understandably reluctant to admit it? The documents show that the industry thought his work might have more impact without such acknowledgement. The fact that he was apparently willing to agree to this arrangement suggests at least two possibilities: that he knew such acknowledgement would damage his own credibility as a scientist, or that he was covering for the industry.

Fields and Chapman point out that Wynder's position on secondhand smoke was "consistent with his own data." Yet, given the ties uncovered by this research, how do we know that the results of his work were not affected by industry influence on the questions to be asked, the study design, conduct of the research, and interpretation of the findings? There are multiple points at which the outcome of research can be

\section{Key points}

- The tobacco industry uses ties with respected scientists and institutions to seek credibility.

- The tobacco industry has repeatedly engaged in unethical scientific and publication practices.

- A growing number of institutions are enacting policies declining research funding from the tobacco industry.

- Given the industry's well reported, repeated efforts to obstruct and obscure science unfavourable to tobacco use, scientists should decline such support. influenced. ${ }^{5}$ The tobacco industry shifted from funding research on secondhand smoke to funding research on other indoor air contaminants when it found that the research on secondhand smoke did not support its positions. ${ }^{6}$ Even when research funded by the industry is of the same methodological rigour as nonindustry funded research, the results tend to favour the industry and unfavourable results are suppressed. $.^{7-9} \mathrm{Al}-$ though Wynder's public position was consistent with his publications, we do not know what went on in all the steps leading up to the publications.

These documents reveal an increasingly cozy relationship between Wynder and the industry, including allowing his name to be used as an author on industry prepared work. Ghost authorship, the hidden participation of scientists in the design, conduct, and reporting of research, raises questions about who is accountable for the research that is published. ${ }^{10}$ The cozy relationship, however, apparently evaporated rather quickly along with funding - as soon as Wynder changed his public views on secondhand smoke and was no longer useful in helping lend credibility to industry positions.

Fields and Chapman's paper serves as a telling example of why academic scientists should not collaborate with the tobacco industry for the development of reduced harm products or for other scientific purposes. The tobacco industry now claims it has turned over a new leaf and is ready to work with legitimate scientists to find the answers to pressing questions about tobacco and health-questions it previously spent decades obscuring with biased, lawyer directed research. The industry's new face must be accepted only at face value; the industry's documents suggest that this is part of a long term strategy aimed primarily at improving its public image. ${ }^{11}$

A growing number of respected research institutions (among them University of Washington, Pennsylvania State University, and the University of Sydney) have established policies excluding tobacco industry research funding, recognising that the industry seeks to profit from the respect and credibility accorded to these institutions. ${ }^{12}$ Based on the

\section{Policy implications}

Scientific organisations and institutions should develop policies prohibiting tobacco industry funding of research. At minimum, to address potential conflicts of interest, full disclosure of funding sources at all stages of the research, including in publications and presentations, should be a requirement. 
WSA CATEGORIZATION FORM

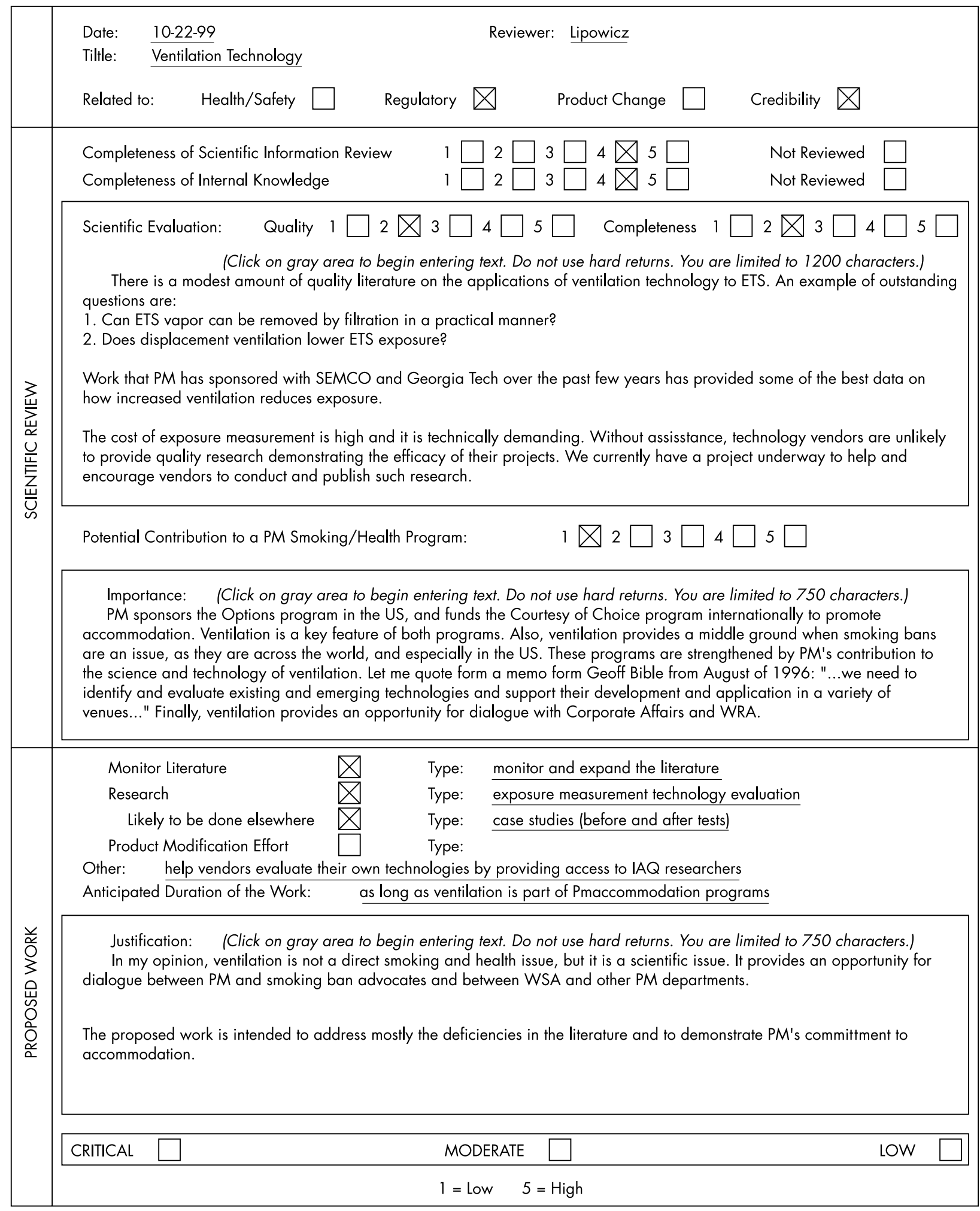

Figure 1 Philip Morris' Worldwide Scientific Affairs Categorization Form. Figure recreated from original document for readability. Original at: http://legacy.library.ucsf.edu/tid/bwil7d00.

increasing emergence of previously secret industry information about the industry's unethical scientific and publication practices, some respected scientific publications are considering whether they will publish research funded by the tobacco industry. In addition, some groups of scientists are challenging industry scientist dominated publications that fail to disclose potential conflicts of interest. ${ }^{13}$

These institutional moves point to the need for scientists to consider how acceptance of tobacco industry research funding helps advance the credibility of the tobacco industry - an industry that continues to spend more than \$1 million an hour, 24 hours a day, 365 days a year, marketing a product that kills millions 
each year when used as intended. Taking tobacco money is a bad bargain for scientists, for their institutions, and for public health. Given the historical record, scintists should decline industry funding.

$J$ Epidemiol Community Health

2003;57:546-548

\section{Authors' affiliations}

R E Malone, L A Bero, University of California,

San Francisco, USA

Correspondence to: Ruth E Malone, Department of Social and Behavioral Sciences, School of Nursing and Center for Tobacco Control

Research and Education, University of

California, San Francisco, Box 1390, UCSF,

San Francisco, CA 94143-1390;

rmalone@itsa.ucsf.edu

\section{REFERENCES}

1 Bero L. Implications of the tobacco industry documents for public health and policy. Annu Rev Public Health 2003;24:267-88.

2 Glantz S, Slade J, Bero L, et al. The cigarette papers. Berkeley, CA: UC Press, 1996.

3 Fields N, Chapman S. Chasing Ernst L Wynder: 40 years of Philip Morris' efforts to influence a leading scientist. J Epidemiol Community Health 2003:57:571-8.

4 Yerger VB, Malone RE. African American leadership groups: smoking with the enemy. Tobacco Control 2002; 11:336-45.

5 Bero L, Rennie D. Influences on the quality of published drug studies. Int J Technol Assess Health Care 1996;12:3

6 Barnes D, Bero LA. Industry-funded research and conflict of interest: an analysis of research sponsored by the tobacco industry through the Center for Indoor Air Research.J Health Polit Policy Law 1996;21:515-42.

7 Bero LA, Galbraith A, Rennie D. Sponsored symposia on environmental tobacco smoke. JAMA 1994:271:612-17.

8 Barnes D, Bero L. Scientific quality of original research articles on environmental tobacco smoke. Tobacco Control 1997; 6: 19-26.

9 Barnes DE, Bero LA. Why review articles on the health effects of passive smoking reach different conclusions. JAMA 1998;279: different conc

10 Hong $M$, Bero L. How the tobacco industry responded to an influential study of the health effects of secondhand smoke. BM 2002;325: 1413-16.

11 Smith E, Offen N, Malone RE. "Altria" means tobacco: Philip Morris's new image. Philadelphia PA: 130th annual meeting, American Public Health Association, 2002. (http://apha.confex.com/apha/ 2002. (http://apha.confex.com/apha/
130am/techprogram/meeting_130am.htm 2002

12 Cohen J. Universities and tobacco money. BN 2001;323: 1-2.

13 Guterman L. Scientists accuse toxicology journal of industry ties. Chronicle of Higher Education 2002;49:A18.

\section{Hazardous effects of tobacco industry funding}

\section{Parascandola}

\section{Public health scientists should be aware of the motives of research sponsors and their potential impact on health}

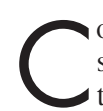
oncern over commercial sponsorship of medical research is at an all time high these days. As academic medical schools become increasingly dependent on financial relationships with the pharmaceutical industry, for example, there have been calls for more stringent standards for research contracts and public disclosure of potential conflicts of interest. ${ }^{1}$ But, so far, severing industry ties completely has not been considered as a serious option.

The case with tobacco, however, is different. A small but growing number of academic institutions (most recently the Harvard School of Public Health and the Arizona College of Public Health) have approved official policies prohibiting their faculty from receiving financial support from tobacco companies and their affiliates. Some prominent funding agencies have also taken a stand. The Wellcome Trust, the American Legacy Foundation, the Public Health Association of Australia, and the National Cancer Institute of Canada will not fund researchers who concurrently receive tobacco industry funding or support. Cancer Research UK is currently considering adopting a similar policy.

Indeed, the tobacco industry is fundamentally different from, say, the chemical or pharmaceutical industries. While
Big Tobacco does not have a monopoly on impure science, it is the undeniable leader in organised subterfuge and manipulation of the scientific process. Over half a century, the industry has used quasi-scientific organisations, such as the Council for Tobacco Research, to promote controversy and uncertainty rather than generate knowledge about the effects of tobacco smoke. Secondly, the tobacco industry has succeeded in evading the kind of comprehensive regulatory structure that exists for chemicals and drugs, which would require manufacturers to meet particular safety and performance standards and allow for close scrutiny of marketing claims. Thirdly, among the enterprises of modern society, tobacco is unparalleled in its toll on human health. And unlike other risky products, the negative effects of tobacco result from the intended use of the product, not from recklessness, misuse, or manufacturing defects.

Given these facts, some insist that there are no circumstances under which it is appropriate to collaborate with or take money from tobacco companies. The Arizona policy states: "Any association between the College of Public Health and the tobacco industry taints the reputation of our College."' Tobacco companies gain public credibility through relationships with prestigious academic institutions, and Cancer Research UK insists that "when a tobacco company benefits, the results are almost certainly negative. Tobacco companies and human well-being are simply incompatible." ${ }^{\prime 3}$

Now Fields and Chapman reveal that one of the most revered figures in the history of smoking and health himself received generous industry support and, moreover, kept quiet about it. ${ }^{4}$ Wynder was coauthor of one of the landmark 1950 lung cancer case-control studies that first brought attention to the hazards of smoking and, throughout the ensuing decades, was an incessant voice for public health action to reduce the morbidity and mortality associated with tobacco use. But, between 1973 and 1995, Wynder's American Health Foundation received over $\$ 5.7$ million in building fund gifts and research support from Philip Morris. In fact, his dealings with the industry began even earlier than Fields and Chapman suggest. In the late 1950s, Wynder began a longtime working relationship with Lorillard scientists that included the evaluation of experimental filters and chemically treated tobacco. ${ }^{5-7}$

But we should be cautious in judging Wynder's conduct from our 21 st century perspective. Firstly, while Wynder was among the first to advocate for harm reduction, he was not alone in his belief that cigarettes could be made substantially less harmful. When testifying before the US Congress in 1957, he urged the passage of regulations to reduce the overall tar and nicotine content of cigarettes by $40 \%$, so that "we can give our public a safer smoking product, and, above all, we can save lives." ${ }^{8}$ By the mid1960s, the Surgeon General, the American Cancer Society, and other leading public health scientists were also voicing support for research into "less hazardous 
cigarettes". ${ }^{10}$ And between 1968 and 1980, the National Cancer Institute's (NCI) Smoking and Health Program spent \$50 million supporting such research.

Secondly, attitudes towards scientific collaboration with industry, particularly the tobacco industry, have evolved significantly over the past 30 years. $^{10}$ The NCI's "less hazardous cigarette" research programme, for example, included industry scientists on its advisory board. At the time, of course, scientists and public health officials did not have the inside knowledge of the tobacco industry's tactics that we have today thanks to whistleblowers and litigation.

Finally, Wynder was fighting an almost single handed battle to promote the fledgling discipline of preventive medicine. In 1969, when the American Health Foundation was created, the NCI did not have any organised programme to fund cancer control activities (that only came later with the 1971 National Cancer Act). Moreover, it was much easier to generate private financial support and political clout for finding a cure for polio than for, say, educating the public about healthy eating habits. Thus, Wynder, who was a pragmatist as well as a visionary, sought aid from those industries that did have an economic stake in the problem.

So what did the cigarette makers stand to gain from courting Wynder? In part, they encouraged Wynder to believe that their interest in "safer" cigarettes was genuine. In turn, Wynder's public statements provided fuel for industrywide claims that regulation was unnecessary because manufacturers were voluntarily doing what the public health community recommended. For example, in 1957 media reports highlighted the fact that some products on the market already met the recommendations of the authoritative Dr Wynder, including Lorillard's "improved" Kent filter cigarette (with the infamous asbestos laden Micronite filter). ${ }^{11}$

Wynder was a sophisticated and politically astute advocate for public health, and he could not have been oblivious to the risks of collaborating with the tobacco industry. Presumably, he believed that doing so would yield a net benefit for public health through harm reduction. But on this point the documents Fields and Chapman have uncovered, fragmented, and incomplete, raise more questions than they answer. Why did Wynder fail to acknowledge his financial ties to Lorillard and Philip Morris when making claims about reduced harm products? Would he have accepted industry funding today? We will never know for sure.

Science, as the saying goes, is not carried out in a vacuum. Therefore, scientists and academic institutions have an obligation to be aware of what a sponsor stands to gain from supporting their work and whether that relationship could be used in a way that is detrimental to public health. In today's environment, where the tobacco industry is desperate to redeem its image to stave off government regulation and jury verdicts, the stakes are higher than ever. Perhaps research grants coming from tobacco companies should carry their own Surgeon General's warning. Caution: Tobacco industry sponsorship may be hazardous to the public's health.

\section{$J$ Epidemiol Community Health} 2003;57:548-549

\section{Author's affiliations}

M Parascandola, National Cancer Institute, 6130 Executive Boulevard, Suite 3109 , Bethesda, MD 20892, USA

Correspondence to: $\operatorname{Dr} M$ Parascandola; paramark@mail.nih.gov

\section{REFERENCES}

1 Moses H, Braunwald E, Martin JB, et al. Collaborating with industry-choices for the academic medical center. N Engl J Med 2002;347:1371-5

2 College of Public Health Tobacco Industry Funding Policy. Available at: http://www.publichealth.arizona.edu/ tobacco/policy.htm (accessed 2 Dec 2002).

3 Cancer Research. Preventing lung cancer: isolating the tobacco industry. Consultation Document Reviewing the Cancer Research UK Code of Practice on Tobacco Funding to Universities. London: Cancer Research UK, 2002

4 Fields N, Chapman S. Chasing Ernst L Wynder: 40 years of Philip Morris' efforts to influence a leading scientist. J Epidemiol Community Health 2003;57:571-8.

5 Jensen CO. [Letter to Dr. E. L. Wynder, Jensen CO. [Letter to Dr. E. L. Wynder,
Memorial Hospital]. 7 Jan 1958. Lorillard. Bates Number: 00066298/6299. http://legacy.library.ucsf.edu/tid/qdm5 le00 (accessed 2 Dec 2002)

6 Spears AW. [Letter to Dr. E. L. Wynder, Sloan-Kettering Cancer Institute]. 17 Mar 1962. Lorillard. Bates No. 87657326/7327. http://legacy.library.ucsf.edu/tid/mnr2 1 e00 (accessed 2 Dec 2002)

7 Davies DL. [Letter to Dr. Alex W. Spears Lorillard Research Center]. 30 Aug 1976 Lorillard. Bates Number: $01421024 / 1025$ (accessed 2 Dec 2002).

8 Testimony of Dr Ernest $\mathbf{L}$ Wynder. False and misleading advertising (Filter-Tip Cigarettes). Hearings before a Subcommittee of the Committee on Government Operations. Washington, DC: US House of Representatives, 85th Congress, First Session July 18, 19, 23-26, 1957.

9 Reviewing progress made toward the development and marketing of a less hazardous cigarette. Hearings before the Consumer Subcommittee of the Committee on Commerce. Washington, DC: US House of Representatives, 90th Congress, First Session, August 23-25, 1967

10 Berridge V. Why have attitudes to industry funding of research changed? Addiction 1997:92:965-8.

11 Filtered for safety. Time 29 Jul 1957. 
Multilevel analytical approaches in social epidemiology: measures of health variation compared with traditional measures of association

\section{J Merlo}

\section{Considering both distribution and determinants of health}

A

$\mathrm{n}$ this issue of the journal Jennifer Ahern et al present the results of a multilevel analysis showing the increased likelihood of preterm birth affecting both African American and white women living in a neighbourhood with deprived socioeconomic characteristics. This increased risk was independent of individual cigarette smoking and modified by socioeconomic characteristics of the women. The authors, taking a multilevel perspective, concluded that examining both neighbourhood and individual socioeconomic factors in combination with behavioural and biological factors is the most adequate way to study determinants of preterm delivery.

\section{MULTILEVEL ANALYSIS WITHOUT MULTILEVEL REGRESSION-IS THE INTRA-NEIGHBOURHOOD CORRELATION* A NUISANCE?}

The study of Ahern et al contributes to the growing stream of current multilevel analysis in modern health epidemiology. However, the analytical approach of Ahern's multilevel analysis does not apply multilevel regression (synonymous with hierarchical regression $)^{2-5}$ for statistical modelling. The authors describe the association between preterm birth and neighbourhood variables by populationaverage regression techniques that account for intra-neighbourhood correlation using a method called generalised estimating equations (GEE). ${ }^{67}$ In this way the authors simply aim to provide acceptable estimates for the standard errors around point estimates (that is, odds ratios, $95 \% \mathrm{CI}$ ), treating the intraneighbourhood correlation as a "nuisance" that needs to be adjusted in the analysis but not explicitly investigated.

Analogously to the study of Ahern, other social epidemiologists have adopted a similar analytical approach, applying SUDAAN statistical software (http://www.rti.org/) to perform multilevel analysis. As in Ahern's study, SUDAAN analyses also consider the variance structure of the data as a necessary "nuisance". These authors' analytical approach and the estimation of the association between neighbourhood characteristics and health are, however, appropriate and formally correct.

*The most fundamental reason for applying special statistical techniques in multilevel analysis is the existence of intraclass (intra-neighbourhood) correlation. The intraclass correlation is a measure of the degree of similarity among the outcomes of members of the same neighbourhood. Individuals living in the same neighbourhood may be more similar to each other than individuals living in other neighbourhoods, as they share a number of economic, social, and other neighbourhood characteristics that may condition similar health status. In this sense neighbourhoods can be consider as "clusters" of individuals sharing a common propensity for similar outcome within clusters. More technically, the intraclass correlation is a variance partition coefficient that indicates the proportion of the total variance (V)-that is, the sum of 1 st level (individual) and 2nd level (neighbourhood) variances in a health outcome that it is accounted for by the 2 nd level variance. 9 Intraclass correlation needs to be accounted for in regression analysis, as in the study of Jennifer Ahern et al. ${ }^{1}$ Otherwise the lack of independence, arising from two sources of variation at different levels (individual and neighbourhood) of the data hierarchy contradicts the assumption for performing traditional regression analysis. If ICC is not considered, the study sample is artificially "inflated" and the standard error of neighbourhood variables underestimated. One can image 100 neighbourhoods with some 50 individuals each (that is, population size $=5000$ individuals). If the individuals within each neighbourhood are exactly similar to each other, but completely different from the individuals in the other neighbourhood (intra-neighbourhood correlation $=100 \%$ ), the effective number of individuals would be 100 rather than 5000 . In other words, if the ICC $=100 \%$, the effective population size will be the number of neighbourhoods, rather than the number of individuals.

$\mathrm{ICC}=\frac{\mathrm{V}_{\text {2nd level }}}{\mathrm{V}_{\text {2nd level }}+\mathrm{V}_{\text {1st level }}}$

Is this the end of the story? Is the only reason for applying complicated statistical techniques so that correct confidence intervals may be obtained? Is the intraneighbourhood correlation only a "nuisance" that needs to be controlled but not investigated? Is knowledge regarding multilevel measures of health variation, like intra-neighbourhood correlation, irrelevant in social epidemiology?

\section{MULTILEVEL MEASURES OF HEALTH VARIATION}

Within social epidemiology, explicit knowledge about intra-neighbourhood correlation is of importance for substantive epidemiological reasons. Estimation of the extent to which individuals within a given neighbourhood are correlated with one another in relation to health (the concept of intra-neighbourhood correlation) yields important information by itself. The more the health of the individuals within a neighbourhood are alike (as compared with individuals in other neighbourhoods), the more likely it is that the determinants of individual health have to do directly with the contextual environment of the neighbourhood, ${ }^{4}$ and/or that strong social processes of contextual/geographical segregation are taking place-that is, similar types of individuals choose or are forced to reside in a given neighbourhood.

The investigation of multilevel measures of health variation (for example, slope variance, modelling of variance, variance partition coefficient, and intraneighbourhood correlation) yield more extended and sophisticated information than traditional measures of association (for example, regression coefficients, odds ratios). ${ }^{89}$ For multilevel logistic regression Larsen has proposed using a median odds ratio (MOR) measure that reflects the second level (that is, neighbourhood) variance and can be used to quantify area effects on individual health. ${ }^{10}$ This author has also proposed the use of an interval odds ratio (IOR) that integrates neighbourhood variation in measures of association. MOR and IOR are intuitive and easy to be interpreted in terms of well known odds ratios. In general, the use of measures of health variation is a rather new but promising methodological approach that needs to be developed in social epidemiology.

When studying individuals nested within neighbourhoods, an ICC $=0 \%$ suggests that the areas are not important determinant of individual health, as the neighbourhoods resemble random samples from the whole population. 


\section{INTERVENTION FOCUSED ON PLACES INSTEAD OF PEOPLE}

Estimation of the extent to which individuals within a given neighbourhood are correlated with one another in relation to health (that is, the concept of intra-neighbourhood correlation) has value in the context of ideas about the efficacy of focusing intervention on places instead of people. Traditional measures of association like odds ratios can say nothing about how individual health variation in the population differs or correlates between neighbourhoods. For example, if an intervention were to focus on a given selection of "high risk" neighbourhoods, when in fact neighbourhood variation was actually a very small part of the total variation, then a very large number of high risk individuals would be missed simple because they reside in apparently middle and low risk neighbourhoods. ${ }^{11}$ In other words, when the intra-class correlation is small, focusing intervention on places may be a rather inefficient strategy. Therefore, by basing our investigation on the size of the intra-neighbourhood correlation, we can evaluate the relative importance of the neighbourhood level for different kinds of outcomes, and can promote resources for community intervention for those health outcomes that are largely determined by the neighbourhood. Traditional measures of association such as odds ratios thus provide an incomplete epidemiological basis for decision making in public health interventions. Nevertheless, analysis of traditional measures of association has been the approach most commonly used in multilevel population health research. ${ }^{12}$

\section{MEASURES OF HEALTH VARIATION AND TRADITIONAL MEASURES OF ASSOCIATION GIVE COMPLEMENTARY INFORMATION}

It is possible to find large traditional measures of effect (regression coefficients, odds ratios) side by side with smaller measures of health variation (neighbourhood variance and intraneighbourhood correlation). ${ }^{13}$ Even more, neighbourhood variables tend to be more "significant" and have smaller confidence intervals when the intraneighbourhood correlation is low. We need to understand that large odds ratios and a low intraclass correlation are not contraintuitive facts, but they give different and complementary information. ${ }^{14}$

Natural neighbourhood differences, even when very small, may give enough contrast of exposure to detect an association and this association is rather independent of the individual variation. The accompanying figure shows that it is possible to imagine a situation when an
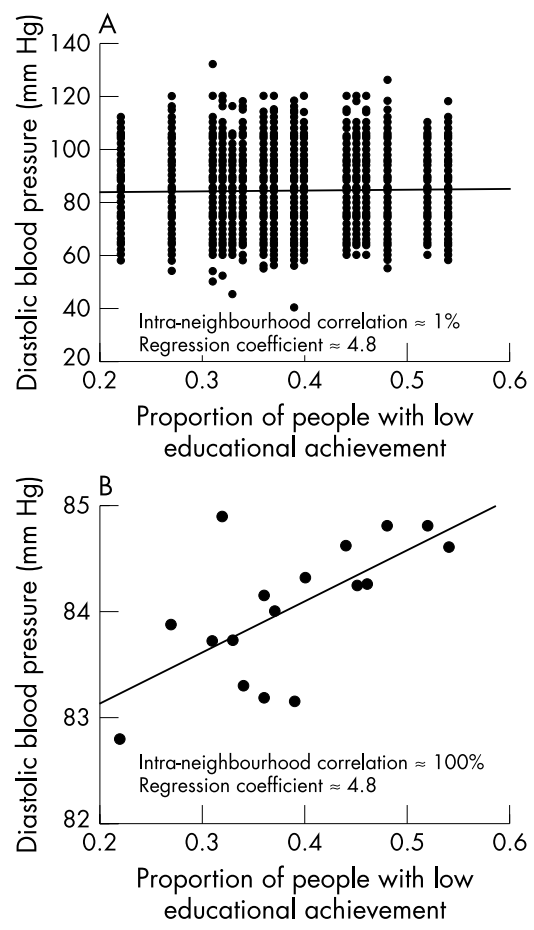

Figure 1 (A) and (B) Present two multilevel analyses showing the exact same association (regression coefficient, $\beta=4.8$ ) between diastolic blood pressure and proportion of people with low educational achievement. However, the size of the intra-neighbourhood correlation ranged from less than $1 \%(\mathrm{~A})$ to $100 \%$ (B). In the first case (A) the areas do not differ more than random samples taken from the whole population, and the geographical environment has almost no effect on the individual outcome. In the second case (B), the clustering of persons in relation to blood pressure is total, and the geographical environment completely influences individual outcome. Despite the large disparity in the size of the intra-neighbourhood correlation, the size of the regression coefficients is similar (that is, $\beta=4.8$ ) in both cases. A similar figure has been previously published in the Journal of Epidemiology and Community Health and is reproduced here with permission."

evident association (regression coefficient, $\beta=4.8$ ) between neighbourhood proportion of people with low educational achievement and blood pressure coexists when the intraclass correlation is very large, but also when it is very small. It is obvious that we can observe the same means with very different variation around these means. In the analysis of traditional measures of association we focus on fixed mean parameters. However, in analysing components of health variation we mainly focus our attention on variance around the means. ${ }^{11}$

\section{CONCLUSIONS}

Certainly broad social and economic forces generate differences among neighbourhoods that shape the distribution of health outcomes. ${ }^{15}$ Strategies of disease prevention need to combine person centred approaches with approaches aimed at changing residential environments. ${ }^{16}$ For this task, traditional measures of association (for example, regression coefficients, odds ratios) between neighbourhood socioeconomic characteristics and individual health are a relevant approach to understanding cross level effect pathways and social determinants of health. ${ }^{17}$ However, when it comes to evaluating multilevel risk distribution and the public health relevance of specific administrative boundaries $^{18}$ (for example, districts, municipalities, neighbourhoods) on different individual health outcomes, multilevel measures of health variation (for example, intra-neighbourhood correlation) present themselves as a new epidemiological approach that may prove very useful in social epidemiology.

\section{ACKNOWLEDGEMENTS}

I want to express my sincere gratitude to Bo Gullberg and Klaus Larsen for revising and commenting on the manuscript.

$J$ Epidemiol Community Health 2003;57:550-552

Author's affiliations

J Merlo, Department of Community Medicine, Malmö University Hospital, Faculty of Medicine, Lund University, S-205 02 Malmö, Sweden

Correspondence to: Dr J Merlo;

Juan.Merlo@smi.mas.lu.se

\section{REFERENCES}

1 Ahern J, Pickett KE, Selvin S, et al. Preterm birth among African American and white women: a multilevel analysis of socioeconomic characteristics and cigarette smoking. J Epidemiol Community Health 2003;57:606-11.

2 Goldstein H. Multilevel statistical models. 3rd edn. London: Hodder Arnold, 2003.

3 Raudenbush SW, Bryk AS. Hierarchical linear models : applications and data analysis methods. 2nd edn. London: Sage Publications, 2002.

4 Sniiders TAB, Bosker RJ. Multilevel analysis-an introduction to basic and advanced multilevel modeling. 1 st edn. Thousand Oaks, CA: Sage Publications, 1999

5 Leyland $\mathbf{A H}$, Goldstein H. Multilevel modeling of health statistics. Chichester: Wiley, 2001

6 Hanley JA, Negassa A, Edwardes MD, et al. Statistical analysis of correlated data using generalized estimating equations: an orientation. Am J Epidemiol

2003;157:364-75.

7 Goldstein H, Browne W, Rasbash J. Marginal vs hierarchical models. Multilevel modelling of medical data. 2002. (http://www.ioe.ac.uk/hgpersonal/ multilevel-medical-tutorial.pdf)

8 Rasbash J, Browne W, Goldstein H, et al. Modelling the variance as a function of explanatory variables. A user's guide to MLwiN. London: Multilevels Models Project, Institute of Education, University of London, 2000:77-88.

9 Goldstein H, Browne W, Rasbash J. Partitioning variation in multilevel models. 2002. (http://www.ioe.ac.uk/hgpersonal/ Variance-partitioning.pdf) 
10 Larsen K, Petersen JH, Budtz-Jorgensen E, et al. Interpreting parameters in the logistic regression model with random effects. Biometrics 2000;56:909-14.

11 Merlo J, Ostergren PO, Hagberg O, et al. Diastolic blood pressure and area of residence: multilevel versus ecological analysis of social inequity. J Epidemiol Community Health 2001;55:791-8.

12 Pickett KE, Pearl M. Multilevel analyses of neighbourhood socioeconomic context and health outcomes: a critical review. J Epidemiol Community Health 2001;55:111-22.
13 Merlo J, Lynch JW, Yang M, et al. Effect of neighbourhood social participation on individual use of hormone replacement and anti-hypertensive medications: a multilevel analysis. Am J Epidemiol 2003;157:774-83.

14 Sampson RJ, Morenoff JD, Gannon-Rowley T. Assessing "neighbordhood effects": social processes and new directions in research. Annu Rev Sociol 2002;28:443-78.

15 Diez Roux AV Merkin SS, Arnett D, et al. Neighborhood of residence and incidence of coronary heart disease. N Engl J Med 2001;345:99-106.
16 Macintyre S, Elleway A. Ecological approaches: rediscovering the role of the physical and social environment. In: Berkman LF, Kawachi I, eds. Social epidemiology. New York: Oxford University Press 2000:332-48

17 Blakely TA, Woodward AJ. Ecological effects in multi-level studies. J Epidemiol Community Health 2000;54:367-74

18 Boyle MH, Willms JD. Place effects for areas defined by administrative boundaries. Am J Epidemiol 1999;149:577-85.

\section{THE JECH GALLERY}

El Salvador: social cost of neoliberal health reform

D espite eight months on strike against health privatisation, popular marches, and a large electoral reverse, the Salvadorian government seems determined on privatisation. The Congress debated a loan from the Interamerican Development Bank to decentralise the Ministry of Public Health (MPH), which was denounced as concealed privatisation by political opposition. Compared with social security reduced cover (15\%), MPH provides services particulary to the poor and extremely poor groups. Its privatisation would enlarge the already disconcerting exclusion of these Salvadorians, condemned by the system to consume the unique item that remains free and abundant in this countrywaste.

(Translation of the sign "Well done Salvadorian . . Consume yours with pride" campaign sponsored by Salvadorian Association of Industrialists, ASI.)

E A Espinoza

Universidad de El Salvador, Final 25 Avenida Norte y Boulevard de Los Héores Edificio de la Rectoría San Salvador, El Salvador espinoza@telesal.ne

1 Espinoza E, Vargas F. On the right to health in El Salvador: no to privatisation. J Epidemio Community Health 2003;57:82.

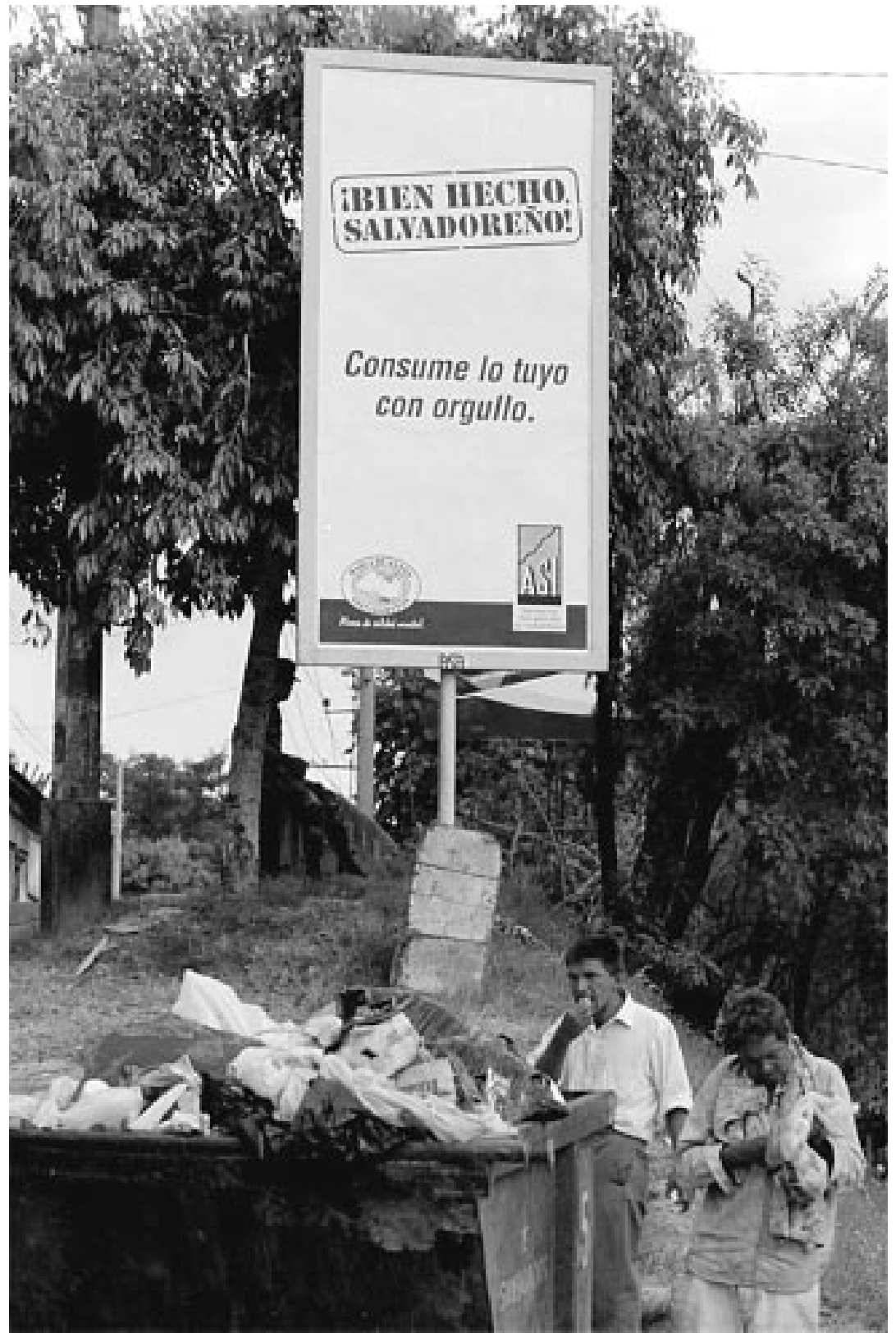

